"This is the peer reviewed version of the following article: Tibor Szabó, Gábor Bencsik, Melinda Magyar, Csaba Visy, Zoltán Gingl, Krisztina Nagy, György Váró, Kata Hajdu, Gábor Kozák, László Nagy, Photosynthetic reaction centers/ITO hybrid nanostructure, Materials Science and Engineering: C, Elsevier, 1 March 2013 which has been published in final form at http://dx.doi.org/10.1016/j.msec.2012.10.031.

(C) 2013. This manuscript version is made available under the CC-BY-NC-ND 4.0 license http://creativecommons.org/licenses/by-nc-nd/4.0/" 


\section{Photosynthetic reaction centers/ITO hybrid nanostructure}

Tibor Szabóa ${ }^{\text {, Gábor Bencsik }}{ }^{\mathrm{b}}$, Melinda Magyara, Csaba Visy ${ }^{\mathrm{b}}$, Zoltán Gingl ${ }^{\mathrm{c}}$, Krisztina Nagyd $^{\mathrm{d}}$, György Váród, Kata Hajdu ${ }^{\mathrm{a}}$, Gábor Kozák ${ }^{\mathrm{a}}$ and László Nagy ${ }^{\mathrm{a}, *}$

${ }^{a}$ Department of Medical Physics and Informatics, University of Szeged, Szeged, Hungary; ${ }^{b}$ Department of Physical Chemistry and Materials Science, University of Szeged, Szeged, Hungary;

${ }^{c}$ Department of Technical Informatics, University of Szeged, Szeged, Hungary; ${ }^{d}$ Institute of Biophysics, Hungarian Academy of Sciences, Biological Research Center, Szeged, Hungary

*Corresponding author: 1nagy@ sol.cc.u-szeged.hu (L.Nagy), tel.: +36-62-544121

Keywords: conducting oxides, indium tin oxide, bio-nanocomposite, reaction center 


\begin{abstract}
Photosynthetic reaction center proteins purified from Rhodobacter sphaeroides purple bacterium were deposited on the surface of indium tin oxide (ITO), a transparent conductive oxide, and the photochemical/-physical properties of the composite were investigated. The kinetics of the light induced absorption change indicated that the $\mathrm{RC}$ was active in the composite and there was an interaction between the protein cofactors and the ITO. The electrochromic response of the bacteriopheophytine absorption at $771 \mathrm{~nm}$ showed an increased electric field perturbation around this chromophore on the surface of ITO compared to the one measured in solution. This absorption change is associated with the chargecompensating relaxation events inside the protein. Similar life time, but smaller magnitude of this absorption change was measured on the surface of borosilicate glass. The light induced change in the conductivity of the composite as a function of the concentration showed the typical sigmoid saturation characteristics unlike if the photochemically inactive chlorophyll was layered on the ITO. In this later case the light induced change in the conductivity was oppositely proportional to the chlorophyll concentration due to the thermal dissipation of the excitation energy. The sensitivity of the measurement is very high, few picomole RC can change the light induced resistance of the composite.
\end{abstract}




\section{Introduction}

Nature developed biological materials for extremely sensitive and specific function and for high capacity work. Their exploitation in technological developments would be definitely beneficial. Recent developments in computer techniques, microelectronics, molecular biology made it possible to use them in nanotechnology.

Different biological materials like drugs [1,2], peptides [3], proteins [4], nucleic acids [5] can be used in combination in nano-hybrid systems as targeted accumulations in vitro and in vivo, e.g. for cancer treatments. Specific biological recognitions are suitable for antibacterial, antiviral targeting by nanomaterials decorated by e.g. antibiotics or antibodies. The unique optical properties of carbon nanotubes can be used for biological imaging [6].

Among the numerous nanostructures (carbon based materials, quantum dots, selfassembled layers, etc.) indium tin oxide (ITO) is of special interest. Thin films of transparent conducting oxides (TCOs) based on indium oxide $\left(\operatorname{In}_{2} \mathrm{O}_{3}\right)$, tin oxide $\left(\mathrm{SnO}_{2}\right)$, as well as their combination in ITO have been widely used in semiconductor and electronic device industry $[7,8]$.

Due to its transparency in the visible range ITO is widely used as electrodes e.g. in liquid crystal displays [9], sensors [10], light emitting devices [11,12] or in photovoltaic solar [13] or electrochemical cells $[14,15]$. Unique possibility for application of the ITO is as component of composite electrode in bio-hybrid systems [16,17]. In hybrid systems it may be possible to harness the advantages of two different materials, bio- or organic materials with inorganic host solids (carrier matrix) at the same time and there is a possibility of the appearance of some new characteristics as well $[18,19]$. Such functional hybrid structures offer the possibility of utilizing transient electronic or photonic interface between the substrate and the carrier matrix.

Future realization of protein-based bio-nanocomposite materials may serve as conceptual revolution in the development of integrated optical devices, e.g. optical switches, micro-imaging systems, sensors, telecommunications technologies or energy harvesting [2022].

Special applications are opened by biological materials which can be activated by light. Attempts are made of using monolayer of photosynthetic reaction center protein (RC) immobilized on ITO in bio-photovoltaic devices [23]. Photosynthetic reaction center protein of plants and bacteria (Fig. 1) is of special interests because it is Nature's solar battery converting light energy into chemical potential in the photosynthetic membrane assuring 
conditions for carbon reduction in cells [24,25]. Although it is developed in nanometer scale, and is working in nanoscopic power, this is the protein that assures the energy input practically for the whole biosphere. The extremely large quantum yield of the primary charge separation (close to $100 \%,[26]$ ) offers a big challenge to use it in nano-devices.

The capture of light energy by bacteriochlorophylls in photosynthetic bacteria is followed by separation of positive and negative charges within the $\mathrm{RC}$ in the state of $\mathrm{P}^{+} \mathrm{BPheo}^{-}$then $\mathrm{P}^{+} \mathrm{QA}^{-}$. Here $\mathrm{P}^{+}$is the oxidized primary donor, a specialized bacteriochlorophyll dimer, $(\mathrm{BChl})_{2}$, $\mathrm{BPheo}$ is the first electron acceptor, a monomer bacteriopheophytin, and $\mathrm{Q}_{\mathrm{A}}^{-}$is the reduced quinone type primary electron acceptor. The separated charges are then further stabilized in form of a $\mathrm{P}^{+} \mathrm{Q}_{\mathrm{B}}{ }^{-}$redox state, where $\mathrm{Q}_{\mathrm{B}}{ }^{-}$is the reduced secondary quinone (Fig. 1, for reviews see, e.g., refs [27-29]). Although the quantum efficiency of the primary charge separation is close to one, the physical parameters of the electron transport within the protein depend on the type of the $\mathrm{RC}$ and on the environmental factors. Specific molecules (such as detergents, lipids, inhibitors, CNTs, etc.) bind to specific sites of the RCs of purple bacteria, [30-32] thus they modify the kinetics and energetics of the charge stabilization.

There are several evidences that RCs can be attached to nano structures and there is an electronic connection between the two types of materials [30,33-35]. The key questions of researches these days are: new applications, reproducibility of the measurements and stability - mainly that of the biological component. Although biological materials in general are disregarded in technical applications because of their fragile nature, they offer special advantages which can be exploited in bioelectronic applications [21]. Results of optical and electro-chemical investigations on RC/ITO bio-nanocomposite materials will be presented here.

\section{Experimental}

\subsection{Sample preparation}

Rhodobacter (Rb.) sphaeroides R-26 purple bacterial cells were grown photoheterotrophically. RCs were prepared after solubilization of the photosynthetic membranes by detergent (LDAO, $N, N$-dimethyldodecylamine- $N$-oxide, Fluka) and purified by ammonium sulfate precipitation, followed by DEAE Sephacel (Sigma) anion-exchange chromatography [36]. After preparation, the $\mathrm{RC} \mathrm{Q}_{\text {в }}$ site was reconstituted by the addition of 
ubiquinone-10 (UQ-10, 2,3-dimethoxy-5-methyl-6-decaisoprenol-p-benzoquinone, Sigma) and concentrated by centrifuge filter (Whatman VectaSpin 3, $10 \mathrm{kDa}$ exclusion) to 80-100 $\mu \mathrm{M}$. For optical spectroscopy, the RC suspension was diluted to $1 \mu \mathrm{M}$ in detergent suspension (10 mM TRIS, $100 \mathrm{mM} \mathrm{NaCl}, 0.01 \%$ LDAO, pH 8.0). In order to deposit RCs on to ITO the detergent was dialyzed out and calculated amount of purified RCs in the range of $10^{-6}-10^{-1}$ $\mu \mathrm{M}$ were dried on the surface of the wafer under the stream of $\mathrm{N}_{2}$.

ITO (Cat No: CEC020B) was purchased from Praezisions Glas \& Optik GmbH (Iserlohn, Germany). This material is prepared by sputter-coating a thin conductive layer of indium tin oxide onto high quality borosilicate glass substrate.

\subsection{Measurements}

\subsubsection{Atomic force microscopy}

In order to visualize the binding of the protein to ITO atomic force microscopy (AFM) investigations were carried out. AFM images were taken with an MFP-3D atomic force microscope (Asylum Research, Santa Barbara, CA). The scanning was performed in AC (tapping) mode with an Olympus cantilever AC160 (Tokyo, Japan) under air dried conditions [30,37]. The sample was set to the ground potential.

\subsubsection{Optical Spectroscopy}

Flash-induced absorption changes were measured routinely by a single-beam kinetic spectrophotometer of local design $[32,38]$. The $\mathrm{P} / \mathrm{P}^{+}$redox changes of the primary electron donor bacteriochlorophyll dimer (P), and the electrochromic response of the absorption of bacteriopheophytins (BPheo) to the formation of the $\mathrm{Q}_{A}{ }^{-} \mathrm{Q}_{B}$ and $\mathrm{Q}_{A} \mathrm{Q}_{B}{ }^{-}$states $[30,32,39,40]$ were detected at $771 \mathrm{~nm}$.

Steady state absorption spectra of ITO wafers with or without RCs were measured by Unicam UV4 double beam spectrophotometer in the range of 250-900 $\mathrm{nm}$. In order to minimize the light scattering effect the sample holder close to the detector was used.

\subsubsection{Measuring conductivity}

Light induced change in the conductivity of RC/ITO composite film was measured by a Keithley 2400s multimeter with seven digits resolution and four points connection. A constant $10 \mathrm{~mA}$ current was set and the voltage was measured. Data are represented in ohms. The whole measurement was regulated through the USB port of a computer by using the 
home developed software (http://www.noise.physx.u-szeged.hu/). Sample was illuminated by a $250 \mathrm{~W}$ tungsten lamp filtered by band-pass filter centered at $400 \mathrm{~nm}$ [34]. The infrared component of the excitation light was filtered out.

\section{Results and discussion}

\subsection{Structural investigation}

Fig. 2 shows the AFM image of the surface of the ITO covered and not covered by the RC protein. The clean ITO surface shows microcrystals with little roughness and more homogenous landscape with only small variation $(3.5-5 \mathrm{~nm})$ in the height distribution. Part of the wafer which is covered by the RC shows more roughness, indicating more or less uniform coverage by the protein. The variation in height section corresponds to the size of the RC protein, about $10 \mathrm{~nm}$, which was published earlier [30,41].

\subsection{Spectroscopic characterization of the RC/ITO complex}

\subsubsection{Steady state absorption spectra}

There are two reasons for measuring the optical spectrum of the RC/ITO composite layer. On the one hand, by calculating the absorption coefficient, $\alpha$, the carrier characteristics can be estimated [42-45].

Conductivity of TCO materials is generated by two mechanisms. In ITO oxygen vacancies can act as electron donors or tin ( $\mathrm{Sn}$ ) substitution of indium (In) assures excess electrons. Conducting mechanisms of these oxides depend strongly on the grain and layer structure of the ITO, consequently, on the deposition technique, the quality and prehistory of the film, which can be characterized by measuring the optical properties of the sample in the UV-visible wavelength range [44-47].

On the other hand, the RC has characteristic absorption in the blue and in the near infrared. Fig. 3 shows that under certain conditions the mutual excitation of the ITO and RC is possible to perform. Excitation of the RC/ITO system by the $400 \mathrm{~nm}$ light initiates both a $\mathrm{P}^{+} \mathrm{Q}^{-}$redox pair within the protein (here $\mathrm{P}^{+}$is the oxidized $\mathrm{e}^{-}$donor, $\mathrm{Q}^{-}$is a reduced $\mathrm{e}^{-}$ acceptor) and electron excitation within the ITO. It is reasonable to assume that there is an interaction between the charge carriers within the protein and the ITO. 


\subsubsection{Absorption kinetics}

Fig. 4 shows the kinetics of the flash-induced absorption changes measured at $771 \mathrm{~nm}$ of the RCs under different experimental conditions. Results measured for the RC/ITO composite are compared to the data obtained for RC deposited on borosilicate glass and solubilized in detergent micelles as control samples. A shift in the electrochromic response of the BPheo absorption due to the electric field perturbation at $771 \mathrm{~nm}$ is associated with the charge-compensating relaxation events within the protein $[30,32,39]$.

The time window is very wide (it covers 6 orders of magnitude), thus both the $\mathrm{P}^{+} \mathrm{Q}^{-}$ $\mathrm{Q}_{B} \rightarrow \mathrm{P}^{+} \mathrm{Q}_{\mathrm{A}} \mathrm{Q}_{\mathrm{B}}{ }^{-}$electron transfer and the accompanied reactions (forward electron transfer resulting the separation of charges, fast phase) and the $\mathrm{P}^{+} \mathrm{Q}_{\mathrm{A}} \mathrm{Q}_{\mathrm{B}}{ }^{-} \rightarrow \mathrm{PQ}_{\mathrm{A}} \mathrm{Q}_{\mathrm{B}}$ charge recombination (slow phase) can be followed in one plot of the logarithmic time scale. The time resolution was limited to few microseconds for the measurements in solution and few tens of microseconds in dried samples, mainly due to light scattering. The measured curves were analyzed in terms of sum of first order kinetic reactions, $A(t)=A_{i} \exp \left(-k_{i} t\right)$, where $A(t)$ is the signal amplitude as a function of time, $t, k_{\mathrm{i}}$ and $A_{\mathrm{i}}$ are the rate and the weight of the $i^{\text {th }}$ component of the signal. The kinetic parameters (amplitudes and rate constants) obtained from multiexponential decomposition are summarized in Table 1.

Although the coupling of the electron transport and protein dynamics has been the subject of several interesting works $[48,49]$, it is not clear in the literature which changes are limiting the intraprotein electron transport. It is evident now that the electron transfer induces rearrangements of partial charges and/or hydrogen bonding networks within the protein [27] and might be kinetically gated by these conformational rearrangements $[39,40,50]$. The protein relaxation after flash excitation can cover a large time range (up to $100 \mathrm{~ms}$ ), as revealed by delayed fluorescence measurements [51].

The kinetic traces of the $771 \mathrm{~nm}$ absorption change are strongly affected by environmental factors. The obvious effects are $\mathrm{pH}$, temperature, viscosity, ionic strength in solution indicating the role of conformation changes and rearrangement of the hydrogen bonding network $[39,40,50]$. In lipid environment, mimicking that of the in vivo conditions, the energetics of the stabilization of the light induced charge pair is modified, which has a thermodynamic control of the $\mathrm{e}^{-}$-transfer [32,52]. Attachment of the RC to carbon nanotubes has also an effect on the relaxation kinetics with different mechanisms [30,34,35].

The absorption change at $860 \mathrm{~nm}$ is a direct measure of the redox state of the primary donor $(\mathrm{BChl})_{2}$. Fig. 4 and the fitting parameters presented in Table 1 show that while there is only a negligible change in the redox state of the primary donor after the flash excitation 
(there is only small change in the fast transient at $860 \mathrm{~nm}$ ) both the amplitude and the rate of the pheophytine shift is larger when the RC is deposited on the ITO.

Due to the larger scattering we could not resolve two kinetic components of the fast phase of the ITO/RC sample, which can be done in solution, but it clearly appears that the rate of the forward electron transfer, $k_{\mathrm{AB}}$, increased considerably as compared to the RC on the glass. $k_{\mathrm{AB} \text {,slow }}=448 \mathrm{~s}^{-1}$ and $1711 \mathrm{~s}^{-1}$ on glass and on ITO, respectively. The accelerated transient in the $771 \mathrm{~nm}$ absorption together with the small change in the kinetics at $860 \mathrm{~nm}$ indicates that the electrostatic interaction, rather than the oxidation/reduction coupling between the RC and ITO can be accounted for the processes after the flash excitation.

\subsection{Electric properties}

In order to check the nature of the electric interaction between the RC and the ITO the conductance was measured if a constant $10 \mathrm{~mA}$ DC current was set through the ITO wafer covered by thin layer of the protein and the voltage was measured under excitation by continuous (cw) blue light (centered at 400 nm, Figs. 5 and 6).

If the clean ITO is illuminated by the $\mathrm{cw}$ blue light the resistance decreases. This decrease is well compensated by RCs deposited on the surface and reaches a saturation level by increasing the RC concentration (Figs. 5 and 6). Increasing the amount of RC in the layer after the plateau is reached the resistance increases again. The resistance change in this phase fits well with the one measured for the ITO covered by the photochemically inactive BChl as a control experiment.

The phenomenon after the flash excitation is very complex and the quantitative description of the measured curves requires more careful calibration experiments, which cannot be the aim of this paper. It is well demonstrated that exciting the photochemically inactive pigments the absorbed energy is dissipated as heat and the temperature change in the system is proportional with the heat dissipation [53]. Indeed, we found this proportionality [34], the resistance of the ITO increases with the temperature in this small temperature range. This fact lets us to conclude that the resistance change in the BChl/ITO system is probably due to the heat dissipation process.

However, if the system performs light induced photochemical changes in the presence of the protein the measured resistance curve is not monophasic. $400 \mathrm{~nm}$ blue light induces $\mathrm{P}^{+} \mathrm{Q}^{-}$charge pair within the protein and causes excitation in ITO. An interaction between the excited electrons and the photoactive cofactors in the protein can be expected after the mutual 
excitation which is manifested by the increase in resistance. If the diameter of the RC is approximated by about $10 \mathrm{~nm}$ the $\mathrm{RC}$ concentration at the plateau can be corresponded to a close contact monolayer coverage by the protein. When the concentration is larger than the one at the plateau than multiple layers are formed and the thermal changes are more accounted.

\section{Summary}

A bio-nanocomposite material was created from purified photosynthetic reaction center protein and conductive metal oxide, ITO. The spectroscopic properties and electric conductivity were measured. This study provides direct evidence that the RC keeps its photochemical activity even if it is dried on ITO. Both the magnitude and the rate of the electrochromic shift in the BPheo absorption increased on the ITO indicating that the change in the electrostatics in the environment has an effect on the kinetics of charge distribution and relaxation processes within the protein. The electric conductivity in the RC/ITO complex upon light excitation decreases. This can be explained by direct electric contact between the metal oxide layer and the protein. The sensitivity of the measurement is very large, few picomole RC can change the light induced resistance of the composite. This bionanocomposite provides a model for new generations of practical applications, e.g. in integrated optoelectronic devices.

\section{Acknowledgement}

This work was supported by grants from Switzerland through the Swiss National Science Foundation (IZ73Z0_128037/1) and Swiss Contribution (SH/7/2/20), by the Hungarian Science Foundation (OTKA, K81180, K72989) and by the National Development Agency, through the project TÁMOP-4.2.1/B-09/1/KONV-2010- 0005.

\section{Bibliography}

[1] R.P. Feazell, N. Nakayama-Ratchford, H. Dai, S.J. Lippard, J. Am. Chem. Soc. 129 (2007) 8438 . 
[2] Z. Liu, A.C. Fan, K. Rakhra, S. Sherlock, A. Goodwin, X. Chen, Q. Yang, D.W. Felsher, H. Dai, Angew. Chem. Int. Ed. Engl. 48 (2009) 7668.

[3] D. Pantarotto, J.P. Briand, M. Prato, A. Bianco, Chem. Comm. 1 (2004) 16.

[4] N.W.S. Kam, H. Dai, J. Am. Chem. Soc. 127 (2005) 6021.

[5] Y. Liu, D.C. Wu, W.D. Zhang, X. Jiang, C.B. He, T.S. Chung, S.H. Goh, K.W. Leong, Angew. Chem. Int. Ed. 44 (2005) 4782.

[6] A. De La Zerda, C. Zavaleta, S. Keren, S. Vaithilingam, S. Bodapati, Z. Liu, J. Levi, T.-J. Ma, O. Oralkan, Z. Cheng, X. Chen, H. Dai, B.P. Khuri-Yakub, S.S. Gambhir, Nat. Nanotechnol. 3 (2008) 557.

[7] C.G. Granqvist, A. Hultaker, Thin Solid Films 411 (2002) 1.

[8] S. Lany, A. Zunger, Phys. Rev. Lett. 98 (2007) 045501.

[9] T.H. Chou, K.Y. Cheng, T.L. Chang, C.J. Ting, H.C. Hsu, C.J. Wu, J.H. Tsai, T.Y. Huang, Microelectron. Eng. 86 (2009) 628.

[10] M. Nagasaka, K. Yosida, S. Takahashi, K. Sato, J. Anzai, Mat. Sci. Engineering, C 31 (2011) 258.

[11] C.D. Müller, A. Falcou, N. Reckefuss, M. Rojahn, V. Wiederhirn, P. Rudati, H. Frohne, O. Nuyken, H. Becker, K. Meerholz, Nature 421 (2003) 829.

[12] G. Gozzi, D.L. Chinaglia, T.F. Schmidt, o.N. Oliveria Jr., Mat. Sci. Engineering, C 31 (2011) 969.

[13] B. O’Regan, M. Grätzel, Nature 353 (1991) 737.

[14] G. Bencsik, Zs. Lukacs, Cs. Visy, Analyst 135 (2010) 375. 
[15] P.S. Toth, Cs. Janaky, Z. Hiezl, Cs. Visy, Electrochimica Acta 56 (2011) 3447.

[16] A. Uygun, L. Oksusz, S. Chowdhurry, V. Bhethanabotla, Mat. Sci. Engineering, C 30 (2010) 868 .

[17] S.A. Kumar, H.W. Cheng, S.M. Chen, S.F. Wang, Mat. Sci. Engineering, C 30 (2010) 86.

[18] K. Hajdu, Cs. Gergely, M. Martin, T. Cloitre, L. Zimányi, K. Tenger, P. Khoroshyy, G. Palestino, V. Agarwal, K. Hernádi, Z. Németh, L. Nagy, Langmuir 28 (2012) 11866.

[19] M. Darder, P. Aranda, E. Ruiz-Hitzky, Advanced Materials 19 (2007) 1309.

[20] L. Fabian, Zs. Heiner, M. Mero, M. Kiss, E.K. Wolff, P. Ormos, K. Osvay, A. Der, Optics Express 19 (2011) 18861.

[21] N. Vsevolodov, Biomolecular electronics, Birkhauser, Boston, 1998.

[22] A. Der, S. Valkai, L. Fabian, P. Ormos, J.J. Ramsden, E.K. Wolff, Photochem. Photobiol. 83 (2007) 393.

[23] Y. Lu, Y. Xu, B. Liu, J. Kong, Biosensors and Bioelectronics 22 (2007) 1173.

[24] R.J. Cogdell, J.G. Lindsay, Tibtech. 16 (1998) 521.

[25] F. Milano, M. Trotta, M. Dorogi, B. Fischer, L. Giotta, A. Agostiano, P. Maroti, L. Kalman, L. Nagy, J. Bioenerg. Biomembr. 44 (2012) 373.

[26] C.A. Wraight, R. Clayton, Biochim. Biophys. Acta. 333 (1974) 246.

[27] P. Sebban, P. Maroti, M. Schiffer, D. Hanson, Biochemistry 34 (1995) 8390.

[28] J.P. Allen, J.C. Williams, FEBS Lett. 438 (1998) 5.

[29] C.A. Wraight, Frontiers Biosci. 9 (2004) 309. 
[30] M. Dorogi, Z. Balint, Cs. Miko, B. Vileno, M. Milas, K. Hernadi, L. Forro, Gy. Varo, L. Nagy, J. Phys. Chem., B 110 (2006) 21473.

[31] M. Trotta, F. Milano, L. Nagy, A. Agostiano, Mater. Sci. Eng., C 22 (2002) 263.

[32] L. Nagy, F. Milano, M. Dorogi, M. Trotta, G. Laczko, K. Szebenyi, Gy. Varo, A. Agostiano, P. Maroti, Biochemistry 43 (2004) 12913.

[33] N. Lebedev, S.A. Trammell, S. Tsoi, A. Spano, J.H. Kim, J. Xu, M.E. Twigg, J.M. Schnur, Langmuir 24 (2008) 8871.

[34] K. Hajdu, T. Szabo, M. Magyar, G. Bencsik, Z. Nemeth, K. Nagy, L. Forro, Gy. Varo, K. Hernadi, L. Nagy, Phys. Status Solidi, B 248 (2011) 2700.

[35] M. Magyar, K. Hajdu, T. Szabo, K. Hernadi, A. Dombi, E. Horvath, L. Forro, L. Nagy, Phys. Status Solidi, B 248 (2011) 2454.

[36] J. Tandori, L. Nagy, A. Puskas, M. Droppa, G. Horvath, P. Maroti, Photosynth. Res. 45 (1995) 135.

[37] Z. Balint, K. Nagy, I. Laczko, S. Bottka, G.A. Vegh, Zs. Szegletes, Gy. Varo, J. Phys. Chem., C 111 (2007) 17032.

[38] M. Lakatos, G.I. Groma, C. Ganea, J.K. Lanyi, G. Varo, Biophys. J. 82 (2002) 1687.

[39] D.M. Tiede, J. Vázquez, J. Córdova, P. Marone, Biochemistry 35 (1996) 10763.

[40] D.M. Tiede, L. Utschig, D.K. Hanson, D.M. Gallo, Photosynth. Res. 55 (1998) 267.

[41] L. Nagy, K. Hajdu, B. Fisher, K. Hernadi, K. Nagy, J. Vincze, Notulae Scientia Biologica 2 (2010) 07.

[42] E. Burstein, Phys. Rev. 93 (1954) 632. 
[43] T.S. Moss, Proc. Phys. Soc., B 67 (1954) 775.

[44] H.R. Fallah, M. Ghasemi, A. Hassanzadeh, H. Steki, Materials Research Bulletin 42 (2007) 487.

[45] A. El Amrani, F. Hijazi, B. Lucas, J. Bouclé, M. Aldissi, Thin Solid Films 518 (2010) 4582 .

[46] S. Laux, N. Kaiser, A. ZoÈller, R. GoÈtzelmann, H. Lauth, H. Bernitzki, Thin Solid Films 335 (1998) 1.

[47] S. Luo, K. Okada, S. Kohiki, F. Tsutsui, H. Shimooka, F. Shoji, Materials Letters 63 (2009) 641.

[48] G. Palazzo, A. Mallardi, M. Giustini, D. Berti, G. Venturolli, Biophys. J. 79 (2000) 1171.

[49] B.H. McMahon, J.D. Müller, C.A. Wraight, G.U. Nienhaus, Biophys. J. 74 (1998) 2567.

[50] M.S. Graige, G. Feher, M.Y. Okamura, Proc. Natl. Acad. Sci. U.S.A. 95 (1998) 11679.

[51] Z. Filus, G. Laczko, C.A. Wraight, P. Maroti, Biopolymers 74 (2004) 92.

[52] F. Milano, M. Dorogi, K. Szebenyi, L. Nagy, P. Maroti, Gy. Varo, L. Giotta, A. Agostiano, M. Trotta, Bioelectrochemistry 70 (2007) 18.

[53] L. Nagy, V. Kiss, V. Brumfeld, S. Malkin, Photochem. Photobiol. 74 (2001) 81. 


\section{Tables}

Table 1 Parameters of components of the absorption change kinetics measured after single saturating flash excitation in a wide ( 7 orders of magnitude) time range. Data were calculated from measured curves presented on Fig. 4.

\begin{tabular}{|c|c|c|c|c|c|c|c|c|c|}
\hline & \multicolumn{2}{|c|}{$\begin{array}{l}\left(\mathrm{Q}_{\mathrm{A}}{ }^{-} \mathrm{Q}_{\mathrm{B}} \rightarrow\right. \\
\left.\mathrm{Q}_{\mathrm{A}} \mathrm{Q}_{\mathrm{B}}{ }^{-}\right)_{\text {fast }}\end{array}$} & \multicolumn{3}{|c|}{$\begin{array}{l}\left(\mathrm{Q}_{\mathrm{A}}^{-} \mathrm{Q}_{\mathrm{B}} \rightarrow\right. \\
\left.\mathrm{Q}_{\mathrm{A}} \mathrm{Q}_{\mathrm{B}}{ }^{-}\right)_{\text {slow }}\end{array}$} & \multicolumn{2}{|c|}{$\mathrm{P}^{+} \mathrm{Q}_{\mathrm{A}^{-}} \rightarrow \mathrm{PQ}_{\mathrm{A}}$} & \multicolumn{2}{|c|}{$\mathrm{P}^{+} \mathrm{Q}_{\mathrm{B}}{ }^{-} \rightarrow \mathrm{PQ}_{\mathrm{B}}$} \\
\hline & $\begin{array}{c}A_{\mathrm{AB}, \text { fast }} \\
(\%)\end{array}$ & $\begin{array}{c}k_{\mathrm{AB}, \text { fast }} \\
\left(\mathrm{s}^{-1}\right)\end{array}$ & $\begin{array}{c}A_{\mathrm{AB}, \text { slow }} \\
(\%)\end{array}$ & $\begin{array}{c}k_{\mathrm{AB}, \text { slow }} \\
\left(\mathrm{s}^{-1}\right)\end{array}$ & $A_{\text {fast }}+A_{\text {slow }}$ & $A_{\mathrm{AP}}(\%)$ & $k_{\mathrm{AP}}\left(\mathrm{s}^{-1}\right)$ & $A_{\mathrm{BP}}(\%)$ & $k_{\mathrm{BP}}\left(\mathrm{s}^{-1}\right)$ \\
\hline susp & 9.1 & $1.5 \mathrm{E}+4$ & 7.3 & 4699 & 16.4 & 2.4 & 8.3 & 81.3 & 0.56 \\
\hline glass & 12.5 & $1.7 \mathrm{E}+4$ & 9.3 & 448 & 21.8 & 71.8 & 8.5 & 6.5 & 0.89 \\
\hline ITO771 & n.r. & n.r. & 39.9 & 1711 & 39.9 & 53.1 & 9.9 & 9.1 & 1.92 \\
\hline ITO860 & n.r. & n.r. & 11.6 & 868 & 11.6 & 82.7 & 10 & 5.7 & 0.86 \\
\hline
\end{tabular}

${ }^{a} \mathrm{RCs}$ of $R b$. sphaeroides R-26 were incorporated into LDAO detergent micelles (susp), dried on the surface of borosilicate glass (glass), and attached to the surface of ITO (ITO). 771 and 860 are the measuring wavelength. $A$ and $k$ are the relative amplitude (normalized to the total signal) and the rate constants of the observed components, respectively. ${ }^{b}$ n.r.: not resolved 


\section{Figures}

Fig. 1. The protein frame and the redox active cofactors of the photosynthetic RCs. $(\mathrm{BChl})_{2}$ : primary electron donor bacteriochlorophyll dimer; BChl: bacteriochlorophyll monomer; BPheo: bacteriopheophytine; $\mathrm{Q}_{\mathrm{A}}$ : primary quinone; $\mathrm{Q}_{\mathrm{B}}$ : secondary quinone. Black arrows: the electron transport route for the charge separation [34].

Fig. 2. Amplitude (A) and phase (B) AFM image of ITO wafer deposited on the surface of glass. Part of the ITO is covered by the RC protein as indicated. Original scan size is $0.8 \mu \mathrm{m}$, measurement was carried out in $\mathrm{AC}$ mode under air dried conditions as described in the Materials and Methods. The section of height image (C) is also shown. Figure (D) shows the AFM image of the individual RC on mica surface [41].

Fig. 3. Steady state absorption spectra of ITO, glass and ITO+glass samples in the UV and visible range as indicated. ITO+glass was measured as purchased. Glass sample was prepared after eliminating the ITO coverage from the wafers by a mixture of concentrated sulfuric acid and $30 \%$ hydrogen peroxide 3:1 solution. ITO spectrum is the difference between ITO+glass and ITO free glass samples. Insert shows the spectrum zoomed out the visible range. For comparison, the spectrum of the RC in LDAO micellar solution (RC) is also indicated.

Fig. 4. Absorption change of RCs of Rb. sphaeroides R-26 dried on the surface of ITO or borosilicate glass plate, after single saturating laser flash excitation measured at $771 \mathrm{~nm}$. For comparison results of two reference measurements, the measured curves at $860 \mathrm{~nm}$ for the ITO sample and that of the RCs in detergent suspension at $771 \mathrm{~nm}$ is also indicated. Figure was taken from [34]. Solid lines are best fits with values listed in Table 1.

Fig. 5. Resistance of ITO without $(0 \mu \mathrm{M})$ or with RCs, as a function of time under continuous light excitation. The concentration of RCs (numbers show it in $\mu \mathrm{M}$ ) and the time when the light was switched on are indicated. The sample was illuminated by continuous $\lambda=400 \mathrm{~nm}$ light, power: $3.2 \mathrm{~W} / \mathrm{cm}^{2}$. 
Fig. 6. Change of the resistance of ITO as a function of the RC (blue filled circles, RC) and bacteriochlorophyll (red filled squares, $\mathrm{BChl}$ ) concentration deposited on the surface. Error is also indicated by the bars. 


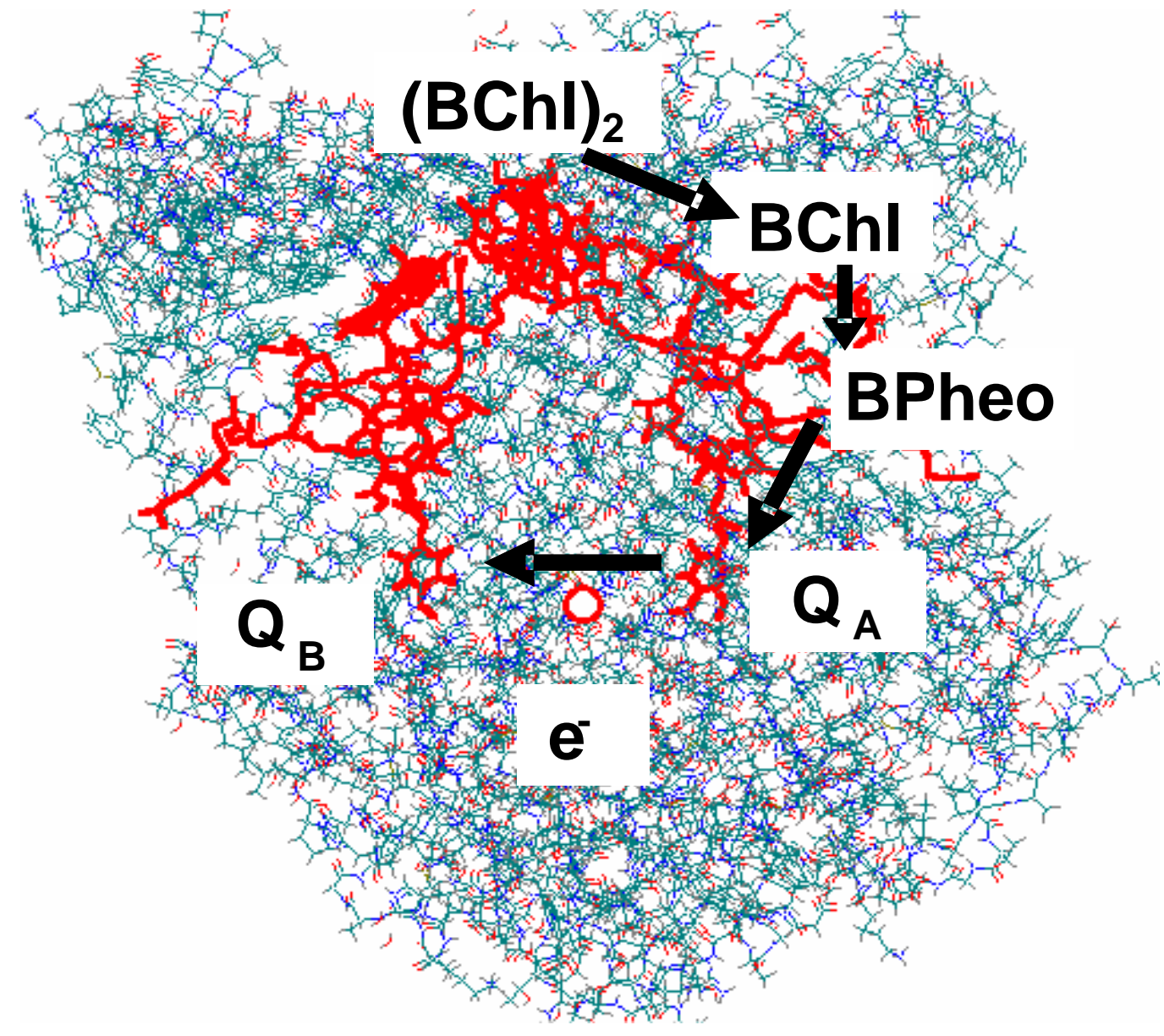

Szabó et al. Fig. 1. 

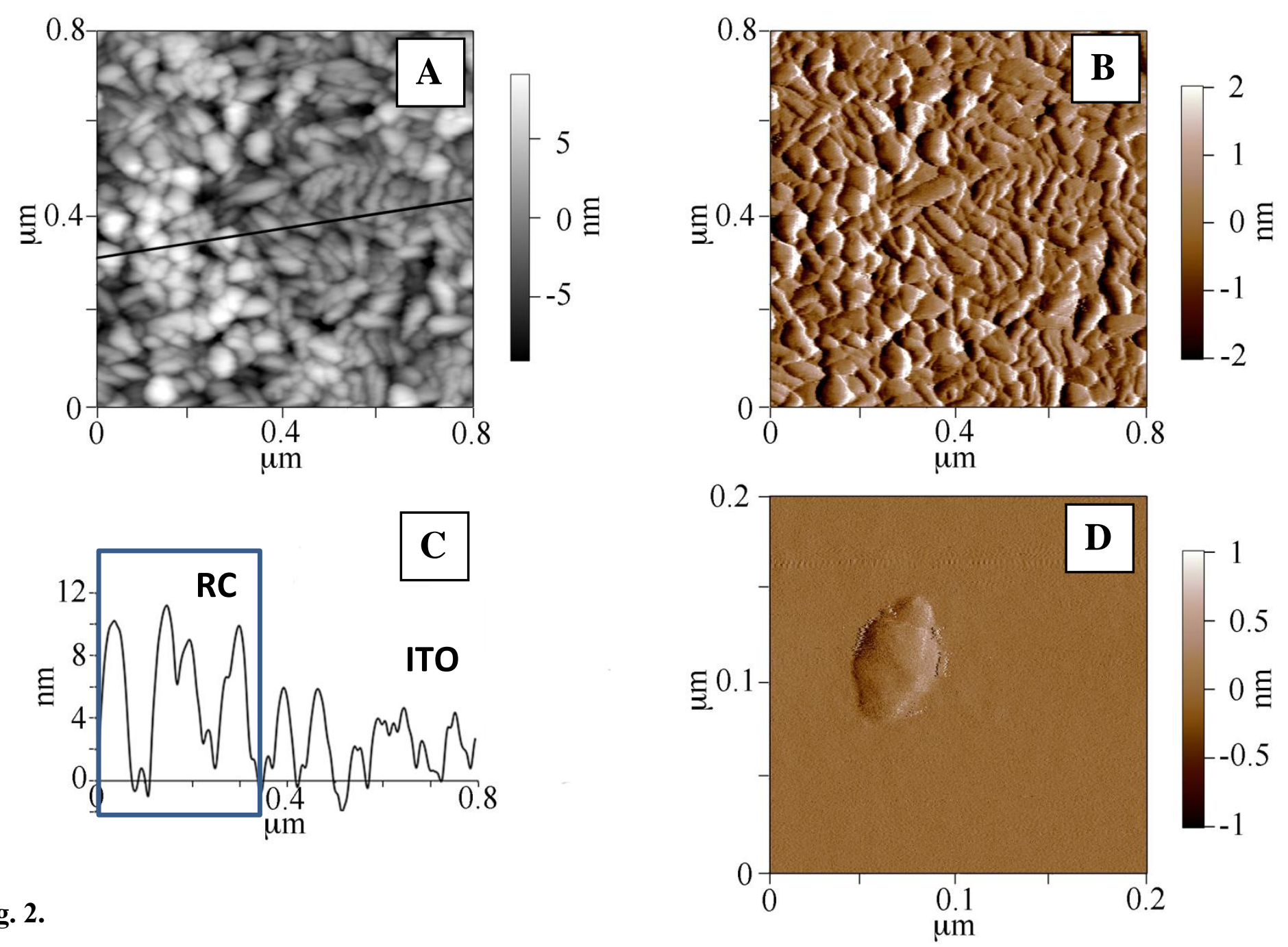

Szabó et al. Fig. 2. 


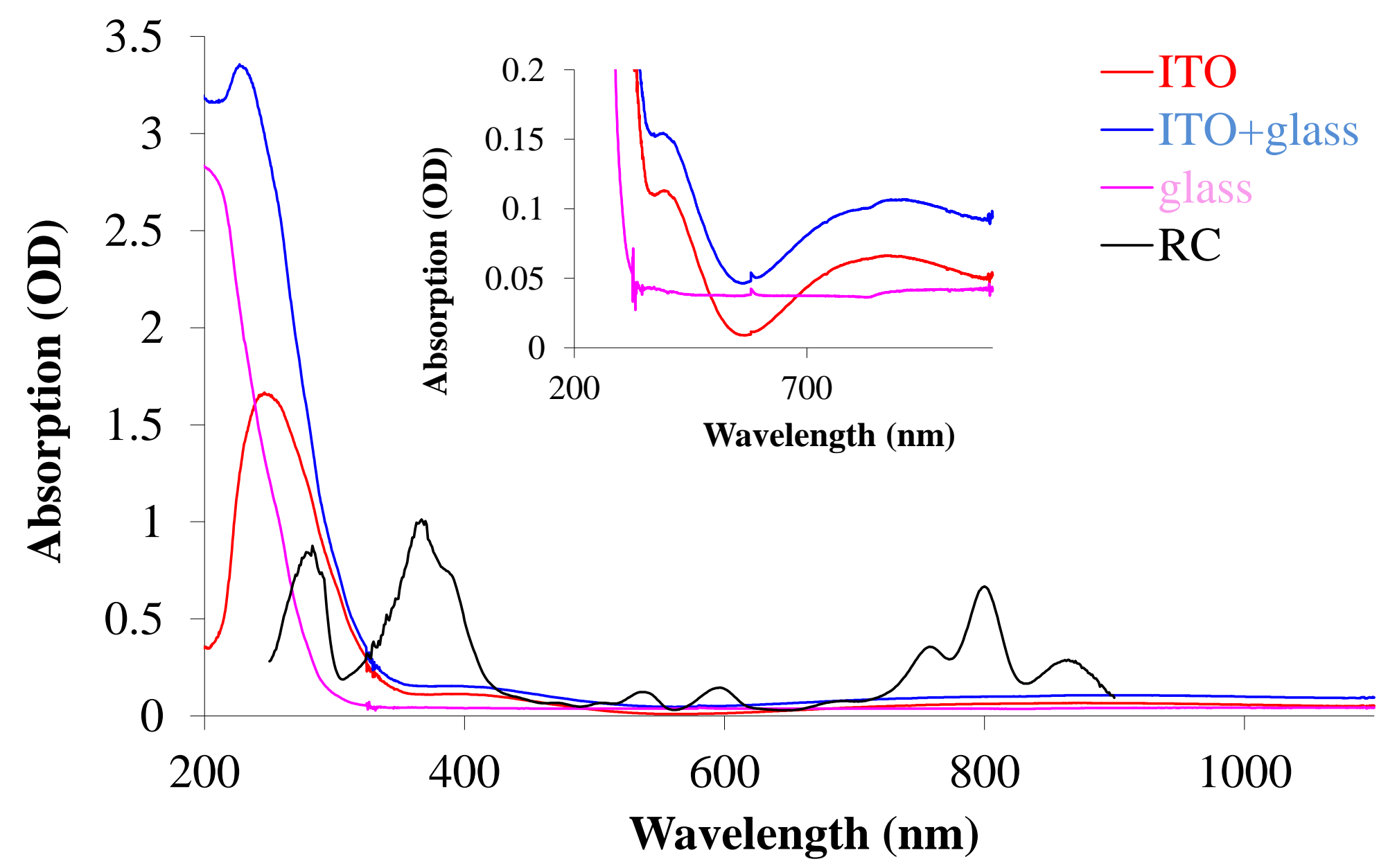

Szabó et al. Fig. 3. 


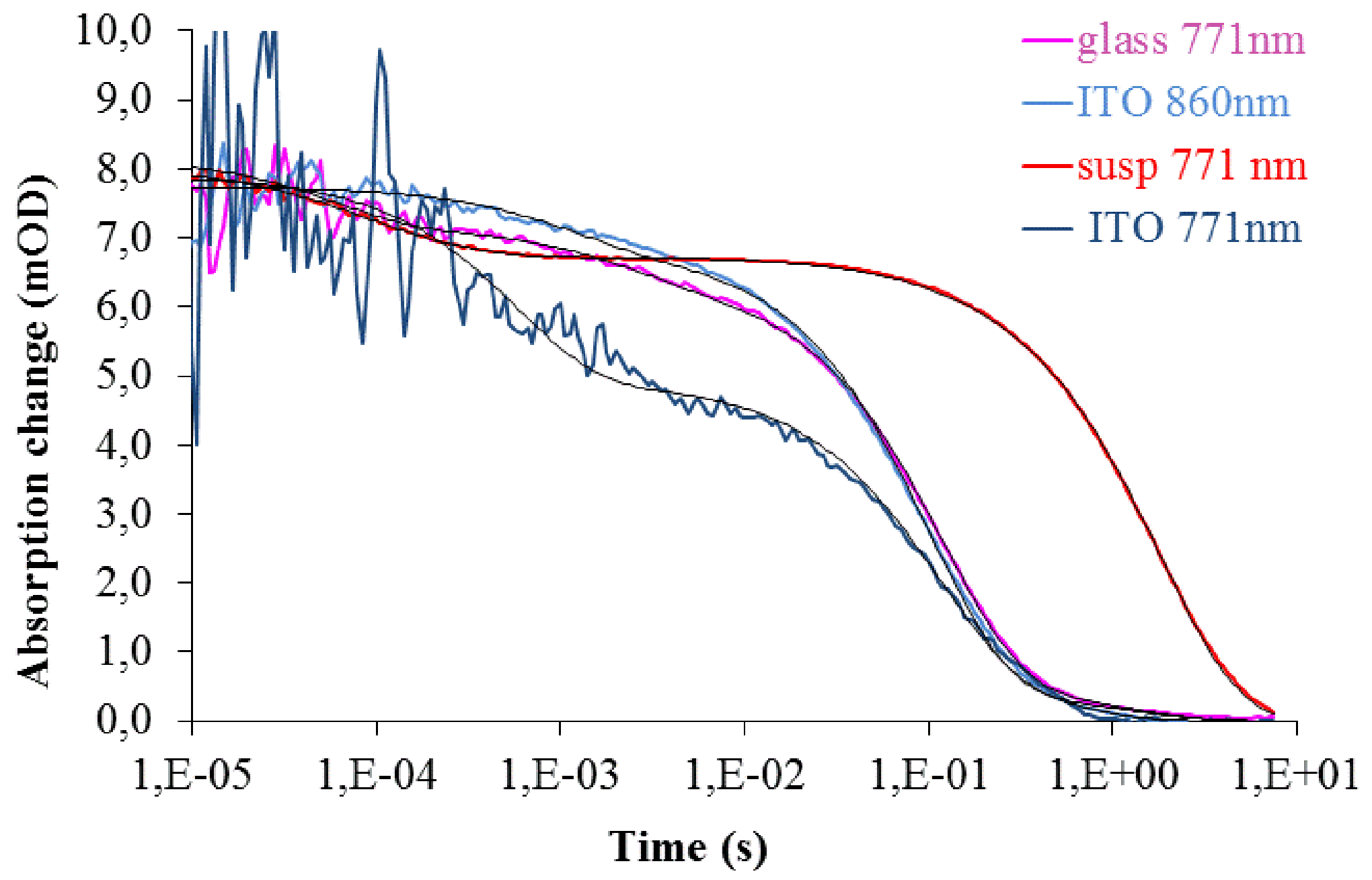

Szabó et al. Fig. 4. 


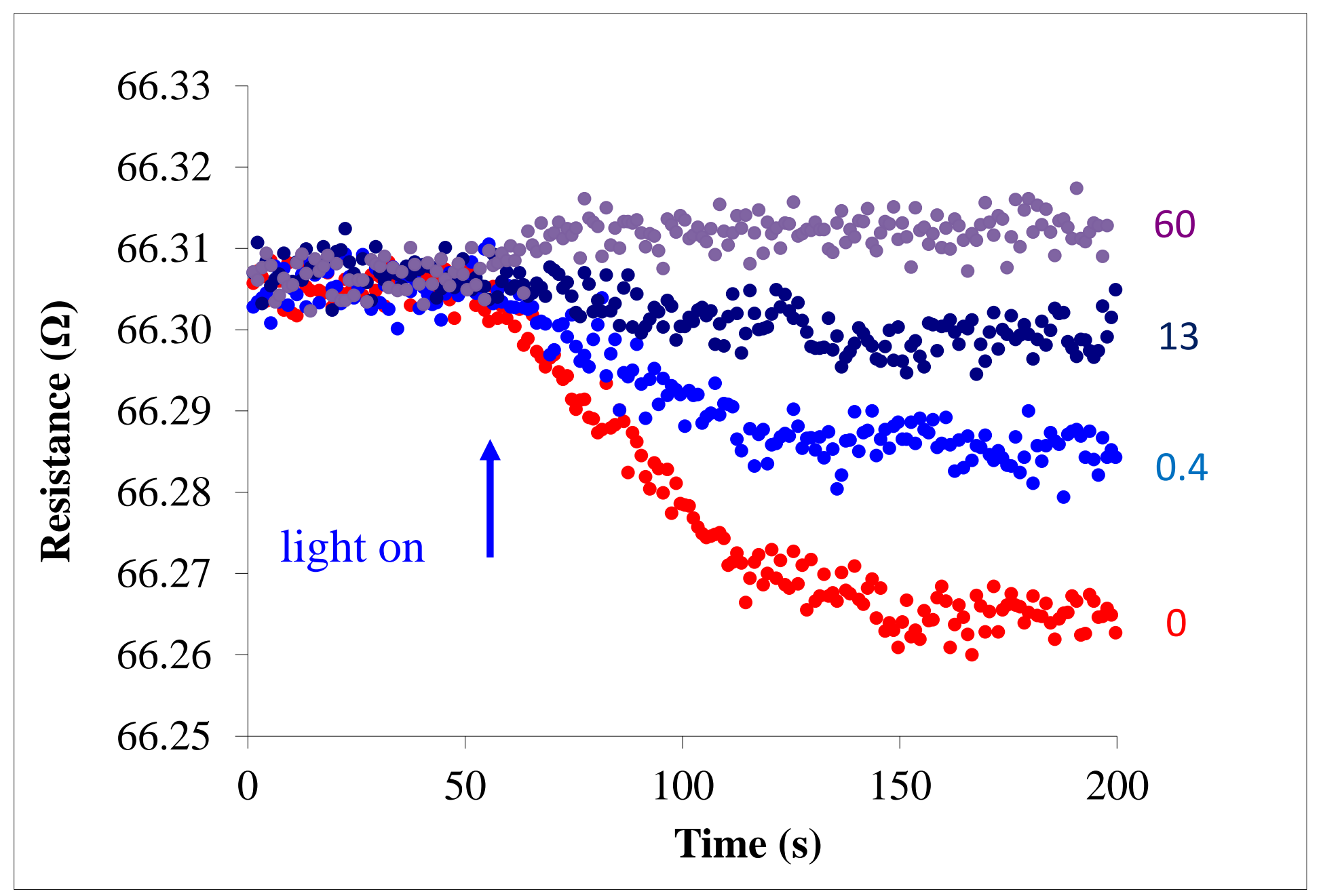

Szabó et al. Fig. 5. 


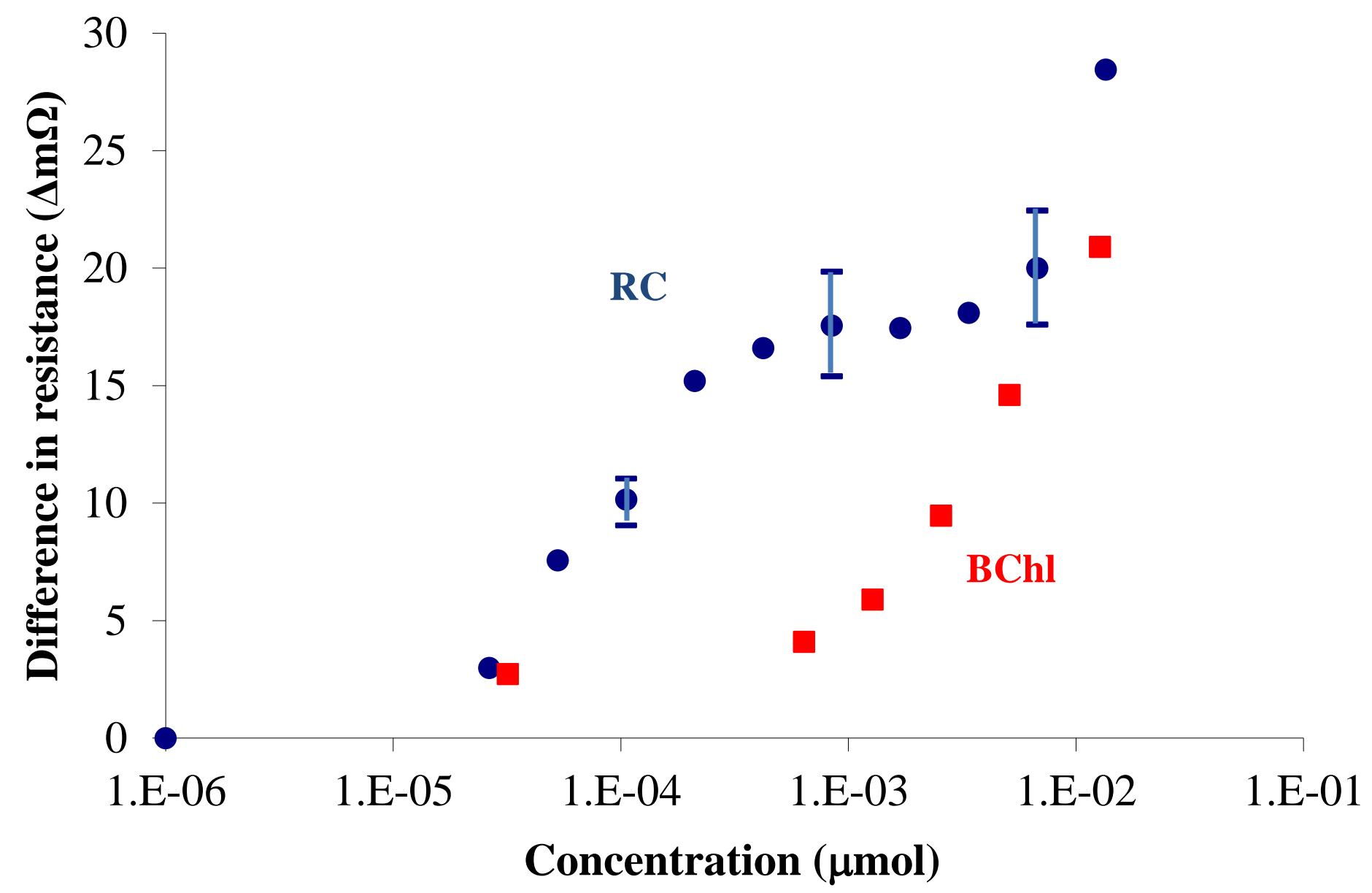

Szabó et al. Fig. 6. 